\title{
Articles for a Special Issue of Public Organization Review (POR) on Local Governments and Intergovernmental Relations in Latin America
}

\author{
Ali Farazmand ${ }^{1}$ \\ Published online: 1 September 2021 \\ (c) Springer Science+Business Media, LLC, part of Springer Nature 2021
}

\section{Background}

There is a tendency to maintain that research in Intergovernmental Relations (IGR) is characteristic of federal states; in fact, for some, it is regarded as a synonym. However, this opinion has lost its intensity. The distance between federal and unitary systems has diminished, since the evidence shows similar tendencies in their political-administrative practices.

While in Latin America we know little about how cooperation and information exchange between levels of government works: whether it is collaborative or confrontational, whether interactions are based on formal or informal agreements -knowing even less about how the government/opposition relationship is established-, national realities show the convergence between federal and unitary systems. This new process has not been sufficiently explored.

The challenge of this monographic issue of Public Organization Review is to understand the "thousand layers" of the multilevel building that recreates the idea of IGRs, where different hierarchies exist between ministries and agencies and between national, regional and local authorities.

\section{Examples of Suitable Topics for the Special Issue}

- Intergovernmental Relations (IGR) in unitary states.

- How government levels cooperate in Latin American countries.

- Which conflicts determine Intergovernmental Relations (IGR) in Latin American countries.

- How is the COVID-19 pandemic influencing Intergovernmental Relations (IGR)?

Ali Farazmand

afarazma@fau.edu

1 Florida Atlantic University, Boca Raton, USA 
- Why do we know so little about Intergovernmental Relations (IGR) in Latin America?

- Intergovernmental Relations (IGR) in Latin American federal states.

- Theories and models in Intergovernmental Relations (IGR). How much do the Latin American cases explain?

- What public policy lessons -learnings- emerge from IGRs in Latin America.

\section{Proposals and Manuscripts}

Proposals should clearly present: (1) a descriptive title; (2) a statement of theme and purpose that includes a problem statement; (3) research questions, including descriptive and explanatory parts; (4) a theoretical/literature basic, briefly outlining central theories and concepts; (5) the 'originality' and significance of the paper; (6) a brief methodology statement that includes, for example, sources of data and tools and methods; and (7) the paper's added value including potential contributions to knowledge (generalizability). Proposals should not exceed the 2-page limit.

Completed manuscripts should not exceed 30 pages double spaced (or 8000 words), inclusive of all tables, figures, and charts. APA style with third person writing is required. Style guidelines are on the POR website.

\section{Timetable to Publication}

Interested scholars are invited to submit proposals of approximately 800 to 1000 words POR by October 30, 2021. Proposing authors will be notified by November 30, 2021.

Draft manuscripts of accepted proposals are due by January 31, 2022.

Authors of draft manuscripts will receive a preliminary review by March 31, 2022 from the Guest and Co-Guest Editors; they will include:

(1) a recommendation to complete the manuscript likely with some suggested revisions; (2) a recommendation to revise and resubmit with more substantive revisions; or (3) a decision that the manuscript will not be accepted - consider submitting it to a different journal. A review with a (1) or (2) recommendation does not guarantee acceptance of the final manuscript.

Final manuscripts are due May 30, 2022, submitted directly to POR.

Final manuscripts will be double-blind reviewed during June and July 2022.

Final reviews and decisions will be posted on POR's Editorial Manager's Site by August 30, 2022.

The Special Issue will be published in POR: Online by September and October 2022 and in print, in either December 2022 issue or Spring 2023 Issue.

Proposals and manuscripts should be submitted to the Editor-in-Chief of POR, or directly to any of the Guest or Co- Guest Editors—see below. 
Questions about the substance or process for proposals, manuscripts, or the Special Issue should be submitted to the Guest editor and/or Co- Guest Editors.

Editor-In-Chief of Public Organization Review (POR): Professor Ali Farazmand, Florida Atlantic University. afarazma@fau.edu

Special Issue Guest Editor: Dr. Mauricio Olavarria-Gambi, Universidad de Santiago de Chile, email: maurico.olavarria@usach.cl

Co-Guest Editors:

Dr. Bernardo Navarrete Yáñez

E-mail: bernardo.navarrete@usach.cl

Universidad de Santiago de Chile

Dr. Daniel Cravacuore

E-mail: dcravacuore@unq.edu.ar

Universidad Nacional de Quilmes, Argentina

POR is a Clarivate Analytic and Web of Science, Scopus, Emergent Science Citation Indexed (ESCI), and Q 2 category listed Peer Reviewed Quarterly Journal.

Publisher's Note Springer Nature remains neutral with regard to jurisdictional claims in published maps and institutional affiliations. 